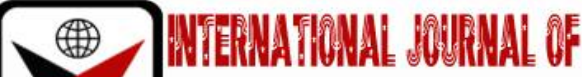

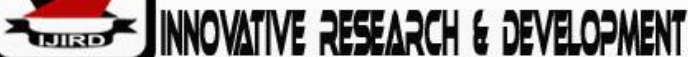

ISSN 2278-0211 (Online)

\section{Comparison of Heat Treatment and Mechanical Properties of Mild Steel Used in Nigeria}

\author{
Umar Gidado \\ Senior Technologist, Department of Mechanical Engineering Technology, \\ Federal Polytechnic Kaura Namoda, Zamfara State, Nigeria \\ Ibrahim Mohammed \\ Senior Lecturer, Department of Mechanical Engineering Technology, \\ Hassan Usman Katsina Polytechnic, Katsina State, Nigeria
}

\begin{abstract}
:
The paper presents the study of carburization of two samples of mild steel from Nigerian Spanish Engineering Limited (NSE) and Top Steel Nigeria Limited (TL) in Ikorodu Lagos, there heat treatment, that consists of annealing, tempering, normalizing and hardening process and the mechanical properties. The paper was aimed at investigating the mechanical properties and the impact strength of the heat-treated mild steel samples after carburizing, the two samples undergoes carburization within a temperature range of $850-950^{\circ} \mathrm{C}$, then quenching process of different quenching method. After quenching all the samples, they undergo mechanical test (Yield Strength, ultimate tensile strength and percentage elongation) using Universal Testing Machine (UTM) and impact strength. The heat treatment result shows a superior improvement on the mechanical properties of the two samples than As Received that shows more ductility toughness and strengths. From the observed result the mechanical properties of the two mild steels samples were found to be influenced by the carburization, whereby NSE present better result than TL with almost 15$20 \%$. Conclusively, heat treatment process increases the mechanical properties of the mild steel, which gives a better construction when using the carburized mild steel.
\end{abstract}

Keywords: Failure, heat treatment, mechanical properties, mild steel, strength

\section{Introduction}

The much failure of engineering construction was due to misused of engineering materials, such as steel. The steel is one of the alloys of iron that contain a carbon ranges from $0.15-1.5 \%$, whereas the plain carbon steel containing about $0.1-0.25 \%$. The steel was used in construction industries due to its abundance in nature in the form of iron oxide $\left(\mathrm{Fe}_{2} \mathrm{O}_{3}\right)$ whereas the compound was converted to iron (Fe) after refining. The iron can exhibit different micro-structures and mechanical properties after undergoing heat treatment and mechanical properties test. Plain carbon steel recorded more than $90 \%$ of the total steel output, due to its ductility, toughness, and is most abundant and cheap material with good machinability which is also, very simple heat treatment (Fadare et al., 2011). These types of steel find applications such in construction of ships, structural buildings, reinforcing rods in concrete etc.

Mild steel has become one of the most extensively studied construction materials in the previous decade. It is used material in the construction company due to its reduce weight, ductility and toughness; this is due to the less carbon content in it (Alabi and Onyeji, 2010). The effect of carbon and heat treatment on the properties of mild steel has been the subject of many investigations. Among the investigations made were based on the carbon, manganese and silicon content, the temperature interpass, impurity elements heat treatment, micro structure, mechanical properties among others on the mild steel (Evans, 1978, 1981, 1086a, 1986b; and Vuik, 1985).

The method of carburizing the steel is among the commonly used method of steel heat treatments. It was performed for thousand years in packing the low carbon wrought iron parts in charcoal, and quench in water, that made the surface to be hard and the core remain ductile and tough of low carbon steel. The heat treatment is the process that considered the combined heating timed and applied cooling method to the given mild steel in order to yield the required properties of the mild steel, such as mechanical properties (yield strength, ultimate tensile strength and percentage elongation). Among the quenching process were normalizing, annealing, tempering and hardening, which are used in modifying the properties of the materials more especially mild steel. Normalizing, is the process of cooling the materials after heated to the required temperature by air cooling, while annealing is heat treatment method used to reduce the mild steel materials and also, refined the grains of the material due to ferrite-pearlite microstructure. The method is used when elongations and a high tensile strength were needed in the materials. The process of this treatment was carried out in order to get pearlite matrix that yield higher strength and hardness than as received mild steel (Adamczyk and Grajcar 2007; Fadare et al., 2011; and Amit, 2014). The strength and wear resistance properties of mild steel were normally based 
on tempering and hardening. In the quenching process, the mild steel would be held at a temperature till the required amount of carbon has been dissolved at a suitable rate. The mild steel has almost $100 \%$ martensite for maximum yield strength in the harden condition; also, the mild steel should be very brittle. But the hardness properties of the mild steel were reduced during quenching by tempering; thereby increasing the ductility and impact strength of the material.

The purpose of study is to investigate the effect of heat treatment of two samples NSE and TL for the tempering, normalizing, annealing, and hardening on the mechanical properties of the two specimens for Yield strength and ultimate tensile strength. The carburizing temperature ranges between $850-950^{\circ} \mathrm{C}$. The main parameters that influence the carburization are the carburizing temperature, holding time, and the carbon content in quenching. In this research two samples of different companies were considered from Nigerian Spanish Engineering Limited (NSE) and Top Steel Nigeria Limited (TL) in Ikorodu Lagos.

\section{Materials and Methods}

Two types of mild steel were used in this research that includes NSE and TL, with the chemical composition As Received and after carburization as shown in Table 1 and 2 respectively. The test specimens were prepared according to the standard and machined based on the standard for impact and tensile testing. This was done according to ASTM's specifications on standard tensile and impact sample dimensions.

\begin{tabular}{|c|c|c|c|c|c|c|c|c|c|c|c|c|c|c|c|c|c|c|}
\hline 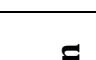 & \multicolumn{18}{|c|}{ Percentage Weight of the Constituent } \\
\hline 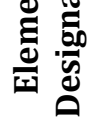 & $u$ & $\bar{\omega}$ & $\sum$ & a & 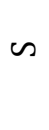 & $\dot{U}$ & نُ & $\bar{z}$ & « & $\Xi$ & ن & $\ddot{E}$ & $\hat{z}$ & $>$ & ๘ี & సี & \& & 可 \\
\hline 䆥 & $\begin{array}{l}0 \\
\hat{n} \\
0 \\
0\end{array}$ & 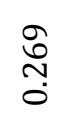 & $\begin{array}{c}\text { ox } \\
0 \\
0\end{array}$ & $\begin{array}{l}\stackrel{m}{m} \\
0 \\
0\end{array}$ & $\begin{array}{l}\stackrel{\infty}{O} \\
\stackrel{\sigma}{0} \\
\stackrel{0}{0}\end{array}$ & $\begin{array}{l}\vec{\infty} \\
0 \\
0 \\
0\end{array}$ & $\begin{array}{l}\hat{0} \\
8 \\
0\end{array}$ & $\begin{array}{l}\text { ¿े } \\
0 \\
0\end{array}$ & 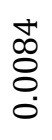 & $\begin{array}{l}\infty \\
\underset{0}{\sigma}\end{array}$ & 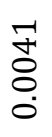 & $\begin{array}{l}\hat{\text { Oे }} \\
\text { ठ } \\
\text { ○ }\end{array}$ & $\begin{array}{l}\text { ̊े } \\
8 \\
0 \\
0\end{array}$ & $\begin{array}{l}\tilde{n} \\
\dot{0} \\
0 \\
0\end{array}$ & $\begin{array}{l}n \\
\stackrel{2}{0} \\
0 \\
0\end{array}$ & $\begin{array}{l}\stackrel{+}{0} \\
\stackrel{0}{0}\end{array}$ & $\begin{array}{l}\widetilde{v} \\
8 \\
0 \\
0\end{array}$ & $\vec{\infty}$ \\
\hline$\vec{F}$ & $\begin{array}{l}\text { ก๊ } \\
\text { } \\
0\end{array}$ & $\underset{\tilde{N}}{\stackrel{\Xi}{0}}$ & $\begin{array}{l}\infty \\
\text { } \\
o \\
0\end{array}$ & $\begin{array}{l}0 \\
\dot{0} \\
0\end{array}$ & $\begin{array}{l}\infty \\
0 \\
0\end{array}$ & $\begin{array}{l}\alpha \\
\delta \\
\delta\end{array}$ & $\begin{array}{l}\stackrel{+}{m} \\
\stackrel{8}{0} \\
0\end{array}$ & $\begin{array}{l}\text { Ta } \\
0\end{array}$ & $\begin{array}{l}\hat{n} \\
\text { \&̊ } \\
\stackrel{0}{0}\end{array}$ & 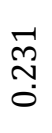 & $\begin{array}{l}\text { m} \\
\text { ஜ } \\
\stackrel{0}{0}\end{array}$ & $\stackrel{m}{\stackrel{m}{8}}$ & $\begin{array}{l}\mathscr{m} \\
\tilde{O} \\
0 \\
0\end{array}$ & $\begin{array}{l}\hat{m} \\
\dot{8} \\
0 \\
0\end{array}$ & $\begin{array}{l}\stackrel{ }{\sim} \\
0 \\
0\end{array}$ & $\begin{array}{l}\tilde{O} \\
\stackrel{0}{0}\end{array}$ & $\begin{array}{l}\text { Tै } \\
\stackrel{8}{0} \\
\vdots\end{array}$ & $\begin{array}{l}\text { oे } \\
\text { oे }\end{array}$ \\
\hline
\end{tabular}

Table 1: Chemical Composition of as Received Samples

\begin{tabular}{|c|c|c|c|c|c|}
\hline \multirow{2}{*}{$\begin{array}{c}\text { Elements } \\
\text { Designation }\end{array}$} & \multicolumn{5}{|c|}{ Percentage Weight of the Constituent } \\
\cline { 2 - 6 } & $\mathbf{C}$ & $\mathbf{M n}$ & $\mathbf{C u}$ & $\mathbf{C r}$ & $\mathbf{F e}$ \\
\hline NSE & 0.171 & 1.05 & 0.29 & 0.098 & 98.391 \\
\hline TL & 0.182 & 1.081 & 0.239 & 0.097 & 98.401 \\
\hline
\end{tabular}

Table 2: Chemical Composition of Carburized Samples

The carburization of the two samples of mild steel (NSE and TL) were embedded in the steel pot in the activated carbon and then sealed tightly with a cover (clay) that prevent carbon monoxide and unwanted gas from furnace during heating process from escaping and entering the pot respectively. The temperature used for each stage in the process in the furnace range from $850^{\circ} \mathrm{C}-950^{\circ} \mathrm{C}$, while the loaded steel pot was placed in the furnace. As the temperature of the furnace reaches the main carburizing temperature, it soaked at that temperature for about $1 / 4$ and $1 / 2$ hour. After that, the pot in the furnace was removed from the furnace and the specimens were quenched using different quenching method (normalizing, annealing, hardening, and tempering).

The quenched samples undergo the mechanical testing, whereby five samples were tested in each case and the average result was recorded. The tensile tests were conducted for the cut samples using a Universal Testing Machine. The load at the sample fracture for each sample was recorded and also, the fractured diameter of each sample. The sample was subjected to load, at a crosshead speed of $1 \mathrm{~mm} / \mathrm{min}$. therefore, the Yield strength and the ultimate tensile strength and percentage reduction of each sample was calculated using the generated data. 


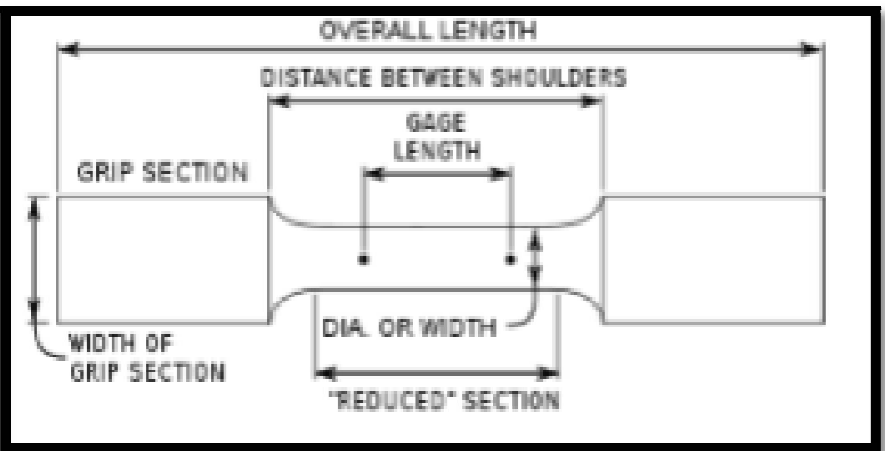

Figure 1: Tensile Testing Specimen

The impact tests were conducted on various treated sample using Impact Testing Machine; five samples were cut for each sample and the average result was recorded. The result was used to determine the impact strength on each sample. In the test, the energy absorbed by each specimen before yielding was recorded accordingly.

The Hardness test was also, experimentally recorded for the two specimens. Rockwell hardness was measured on carburized, heat treated samples of mild steel samples in which five samples were used in each test the average result of each sample was recorded.

\section{Result and Discussion}

The investigative result shown in Figures 2, 3, 4, 5, 6 and 7 depict the comparison of carbon contents in the two samples, the hardness test result, impact test result. Yield strength test result, ultimate tensile strength test result, and a percentage elongation of the samples respectively after undergoing different types of heat treatment.

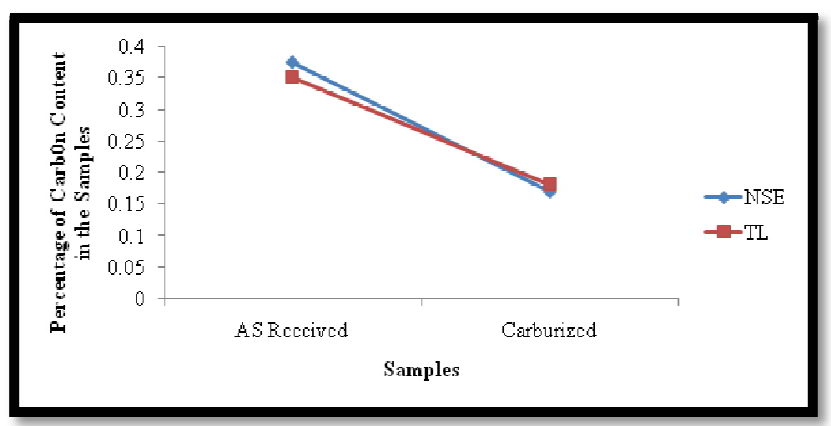

Figure 2: Carbon Content in the Mild Steel

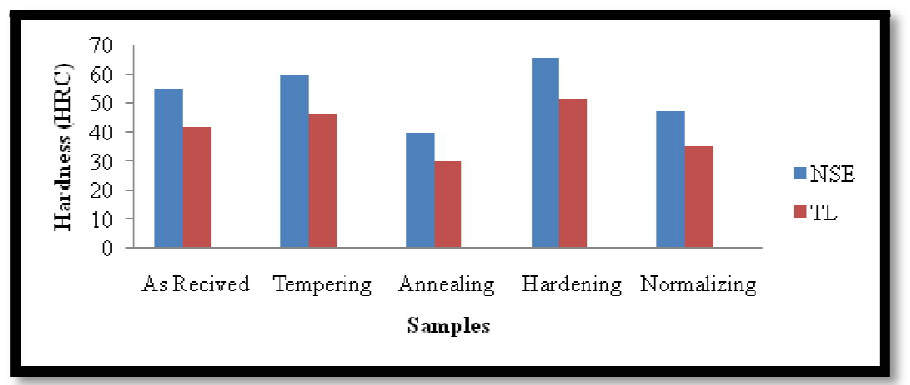

Figure 3: Hardness Test Result

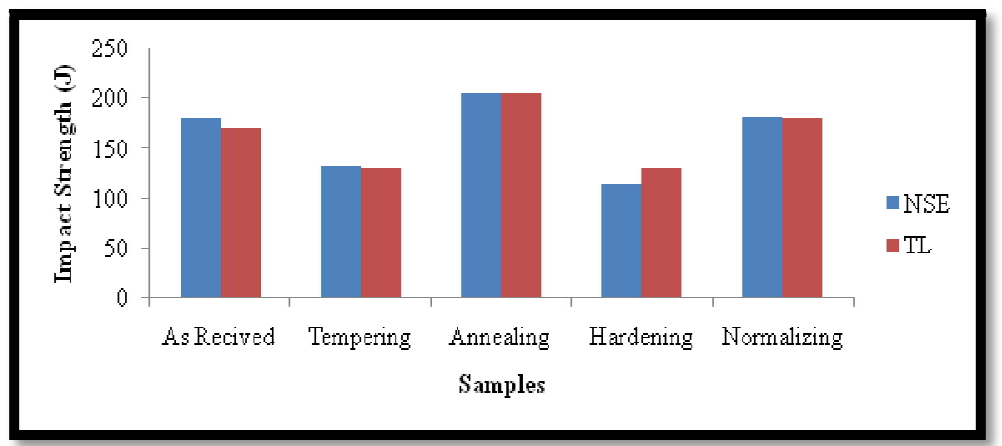

Figure 4: Impact Strength Test Result 


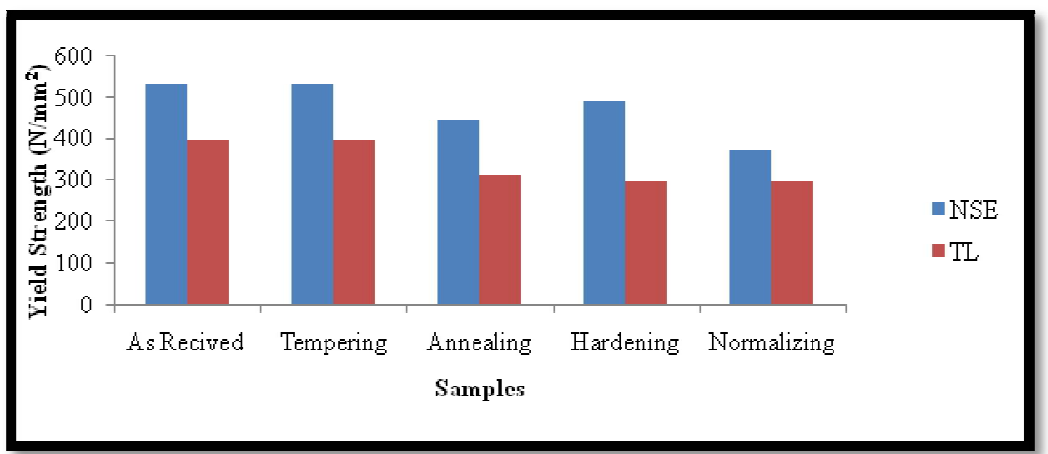

Figure 5: Yield Strength Test Result

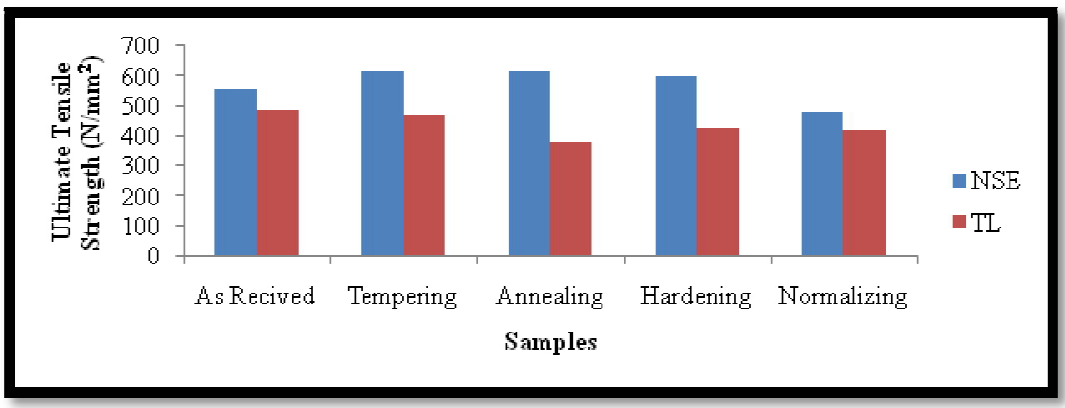

Figure 6: Ultimate Tensile Strength Test Result

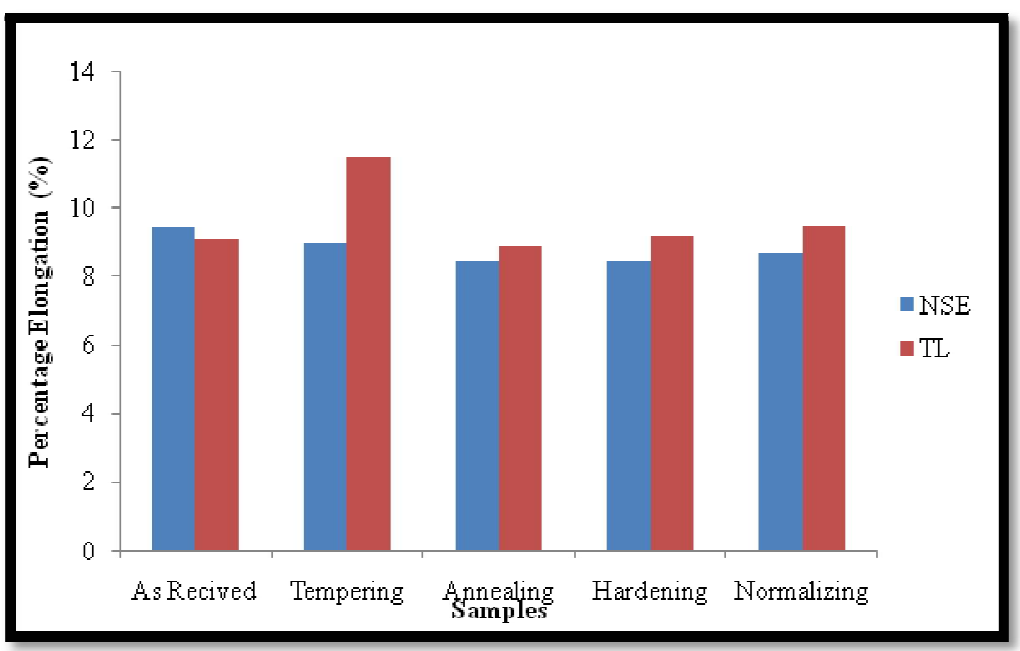

Figure 7: Percentage Reduction Test Result

From the obtained result, clearly it shows that the carbon content in the two samples reduces as the samples were treated. This shows that the mild steel has higher weldability, ductility, and toughness with less hardness, strength and resistance to wear as observed in Kutz (2002); and Alabi and Onyeji (2010).

From the hardness test result, NSE sample for hardening test present the highest value of $65.7 \mathrm{HRC}$, which present the highest carbon content in the sample; the least value was on TL annealing sample of $30 \mathrm{HRC}$ as indicated in Figure 3. This shows a less carbon content in the sample. The result shows that the sample would be more suitable for construction, since it has more ductility and toughness than the other samples. The result was in agreement with the results obtained by Alabi and Onyeji (2010).

The impact result indicates that NSE and TL samples has the same value for the sample that undergoes annealing heat treatment process with the highest value of impact strength of $205 \mathrm{~J}$. the least impact strength was obtained by NSE sample for hardening; which shows less carbon content of the sample. The sample shows that it has less brittleness and it is tougher than the other samples. It is also, observed that the impact energy reduces as the temperature in carburization increased as reported in Fatai et al. (2009).

From the yield strength observed from Figure 5, it shows that some of the samples has higher percentage of carbon as recommended by the standard, steel the strength were acceptable for construction based on the standard. The AS Received sample has higher yield strength than the heat-treated samples with normalizing having the least Yield strength. The result was in agreement with the result obtained by Alabi and Onyeji (2010), where the result of different companies where compared in which the imported medium steel has the highest yield strength.

The ultimate tensile strength also, like yield strength shows higher values of carbon content, but within the limit of the standard. The result of hardening, tempering and annealing shows almost the same value for NSE samples with almost a value of $600-620 \mathrm{~N} / \mathrm{mm}^{2}$. But, it has different values in TL values. It is also, observed that, the ultimate tensile 
strength (UTS) increases with increase in the carburizing and time taken in carburization, this was also, observed in Fatai et al. (2009); and Amit (2014).

The result of percentage elongation in diameter of the two samples shows that TL has the highest value as compared with NSE sample for the heat-treated samples; while for As Received samples NSE has the highest percentage reduction. This shows that the heat treatment has less effect on NSE than TL which shows an increase in percentage in diameter reduction. The highest percentage of reduction in diameter was found on a TL sample that undergoes a tempering heat treatment with $11.46 \%$; while the least percentage reduction occurred on NSE sample that undergoes normalizing heat treatment process. This indicates that NSE for normalizing process has higher content of carbon than the other samples.

\section{Conclusion}

The objective of the research was achieved, whereby the effect of heat treatment of two samples NSE and TL for the tempering, normalizing, annealing, and hardening on the mechanical properties of the two specimens for Yield strength and ultimate tensile strength was investigated. From the research it is concluded that the mechanical properties of mild steels were found to be high due to the carburization of the two types of mild steel. The ultimate tensile strength, yield strength and elongation give good results in normalizing heat treatment of the two types of mild steel. There is increase in percentage elongation on the heat-treated samples than As Received samples. Finally, the treated samples give better result than as received for all the test.

\section{References}

i. Adamczyk, J., and Grajcar, A., (2007). Heat treatment and mechanical properties of low carbon steel with dual phase microstructure' Journal of Achievements in materials and manufacturing engineering. 22(1), 13-20.

ii. Alabi, A.G.F. and Onyeji, L. I. (2010). Analysis and Comparative Assessment of Locally Produced Reinforcing Steel Bars for Structural Purposes. Journal of Research Information in Civil Engineering, 7(2), 49-60.

iii. Amit, K.T., (2014). Effect of Various Heat Treatment Processes on Mechanical Properties of Mild Steel and Stainless Steel. American International Journal of Research in Science, Technology, Engineering \& Mathematics. 8(1), 57-61.

iv. Evans, CM. (1978). Effect of interpass temperature on the microstructure and properties of C-Mn all-weld-metal deposits. IIW- doc. II-A-460-78.

v. Evans, CM., (1981). The effect of carbon on the microstructure and properties of C-Mn- all-weld-metal deposits. HW-doc ll-A-546-81.

vi. Evans, C. M., (1986). Effects of silicon on the microstructure and properties of C-Mn all- weld-metal deposits. Met. Constr. 18(7):438- 444.

vii. Evans, CM. (1986b). Effects of sulfur and phosphorus on microstructure and properties of C-Mn all-weld-metal deposits. Met. Constr. 18(10), 631-636.

viii. Fadare, D.A., Fadare, T.G., and Akanbi, D.Y., (2011). Effect of heat treatment on mechanical properties and microstructure of NST 37-2 steel' Journals of minerals and materials characterization and engineering. 10(3), 299-308.

ix. Fatai, O.A., Simeon, A.I., Isiaka O.O., and Joseph, O.B. (2009). Effects of Carburization Time and Temperature on the Mechanical Properties of Carburized Mild Steel, Using Activated Carbon as Carburizer. 12(4), 483-487.

x. Kutz, M. (2002). Role of alloying Elements in Steel, Hand Book of Material Selection, Kutz Myer Associates, John Wiley and Sons Inc. 45-65

xi. Vuik, I.,(1985). Effects of carbon on the properties and microstructure of weld metal. HW-doc. IX-1375-85. 